\title{
Analysis of debris-flow recordings in an instrumented basin: confirmations and new findings
}

\author{
M. Arattano ${ }^{1}$, L. Marchi ${ }^{2}$, and M. Cavalli ${ }^{2}$ \\ ${ }^{1}$ CNR IRPI, Strada delle Cacce 73, Torino, Italy \\ ${ }^{2}$ CNR IRPI, Corso Stati Uniti 4, Padova, Italy \\ Correspondence to: M. Arattano (massimo.arattano@irpi.cnr.it)
}

Received: 21 November 2011 - Accepted: 13 January 2012 - Published: 22 March 2012

\begin{abstract}
On 24 August 2006, a debris flow took place in the Moscardo Torrent, a basin of the Eastern Italian Alps instrumented for debris-flow monitoring. The debris flow was recorded by two seismic networks located in the lower part of the basin and on the alluvial fan, respectively. The event was also recorded by a pair of ultrasonic sensors installed on the fan, close to the lower seismic network. The comparison between the different recordings outlines particular features of the August 2006 debris flow, different from that of events recorded in previous years. A typical debris-flow wave was observed at the upper seismic network, with a main front abruptly appearing in the torrent, followed by a gradual decrease of flow height. On the contrary, on the alluvial fan the wave displayed an irregular pattern, with low flow depth and the main peak occurring in the central part of the surge both in the seismic recording and in the hydrographs. Recorded data and field evidences indicate that the surge observed on the alluvial fan was not a debris flow, and probably consisted in a water surge laden with fine to medium-sized sediment. The change in shape and characteristics of the wave can be ascribed to the attenuation of the surge caused by the torrent control works implemented in the lower basin during the last years.
\end{abstract}

\section{Introduction}

Field monitoring in instrumented catchments has assumed a central role in debris-flow research. It permits direct collection of field data with a much better accuracy and a greater abundance of information than post-event surveys carried out in ungauged areas, and it also avoids the scale issues that are commonly encountered when trying to reproduce and investigate debris flows in the laboratory. The scientific literature reports a number of experiences on debris-flow moni- toring in natural instrumented channels worldwide, starting from the early eighties till nowadays (Okuda et al., 1980; Pierson, 1986; Zhang, 1993; Zhang and Chen, 1993; Liu and Chen, 2003; McCoy et al., 2010; Suwa et al., 2011; Yin et al., 2011), even though there are many areas around the world where field data regarding debris flows are still scanty (Portilla et al., 2010). In Europe, the Moscardo Torrent, a mountain stream of the Eastern Italian Alps instrumented since 1989 (Arattano, 1999; Marchi et al., 2002) has pioneered the studies on field monitoring of debris-flows. The presence of numerous other instrumented sites in Italy (Tecca et al., 2003; Scotton et al., 2011), in Switzerland, where the Illgraben catchment has become an international leading site for debris-flow field studies (Hürlimann et al., 2003; McArdell et al., 2007; Schlunegger et al., 2009; Berger et al., 2010), in Austria (Kogelnig et al., 2011), in Spain (Hürlimann et al., 2011), and in France (Navratil et al., 2011) shows that debris-flow monitoring is now of topical interest all over Europe.

Amongst the principal findings of debris-flow monitoring research in the Moscardo Torrent, we mention the analysis of critical rainfall thresholds for debris-flow initiation (Deganutti et al., 2000), the improvements in the use of seismic sensors for monitoring and warning purposes (Arattano, 1999, 2003) and the documentation of variations in the shape of debris flow hydrographs from event to event and along the channel (Arattano, 2000, 2003). With regard to this last topic, debris flows are commonly described in literature as waves with a steep front and a typical triangular shape given by the gradual decrease of flow height behind the front. However, data recorded in the Moscardo Torrent have shown that a well-defined debris-flow front is not always present along the whole propagation phase of the phenomenon. The installation of monitoring devices both some hundreds of meters upstream and downstream of the fan apex has allowed us to reveal that the triangular shape of debris flows is a 
feature not necessarily present along the entire debris-flow path. Past observations in the Moscardo torrent allowed us to draw the conclusion that a well-defined debris-flow front and a triangular shape of the debris-flow wave had been consistently observed only on the fan (Arattano, 2003). The data recorded on 24 August 2006 have provided further information on the complex issue of the presence of the debrisflow front during the different propagation phases of the phenomenon along a channel.

\section{The monitoring network}

The basin of the Moscardo Torrent (Fig. 1) is located in the Carnic Alps (north-eastern Italy); it covers an area of $4.1 \mathrm{~km}^{2}$, with a range in elevation from 890 to $2043 \mathrm{~m}$ and an average slope of $63 \%$. A description of the geology, geomorphology, and vegetation cover of the Moscardo basin can be found in Marchi et al. (2002).

The monitoring equipment installed along the torrent has changed during the years. In the following, a brief description of the installations that were present in 2006 is provided. Rainfall was recorded by a raingauge placed in the central part of the basin (Fig. 1). The upstream seismic network (2 in Fig. 1) consists of three vertical-component seismic detectors (two geophones and one seismometer) placed on the ground in an upright position, and it was set along the right bank of a straight torrent reach (Fig. 2). The seismic site was chosen for its easy accessibility due to the presence of a forest road. The upstream detector was placed close to a check dam, the remaining two along the road. The reach has a length of $243 \mathrm{~m}$ and a mean slope of $14.9 \%$. The distance between the first and second sensor is $88 \mathrm{~m}$, between the second and the third sensor $155 \mathrm{~m}$. The first two upstream detectors (G1 and G2) are geophones with a transduction constant of $40 \mathrm{~V} \mathrm{~s} \mathrm{~m}^{-1}$ and a natural frequency of $4.5 \mathrm{~Hz}$ (type 2). The third downstream detector (S1) is a vertical-component seismometer with higher sensitivity, a transduction constant of $160 \mathrm{~V} \mathrm{~s} \mathrm{~m}^{-1}$ and a natural frequency of $1 \mathrm{~Hz}$ (type 1 ). On the fan there are two ultrasonic stations $75 \mathrm{~m}$ apart and a geophone (type 2) placed $63 \mathrm{~m}$ downstream of the second ultrasonic sensor.

Since 1999, important control work has been implemented along the Moscardo Torrent. Check dams were constructed in the middle and lower parts of the main stream within the basin. On the alluvial fan, the channel was lined and widened, and sills were constructed to reduce channel slope.

\section{Methods}

Here we recall some techniques used for the analysis of debris-flow recordings in the Moscardo Torrent. The processing of experimental data is integrated by post-event field observations, aimed at documenting the geomorphic effects of debris flows.
Unlike the flow stage data measured by the ultrasonic gauges, the recordings of the seismic sensors have to be processed in order to obtain variables suitable for the analysis and interpretation of debris-flow behaviour. Seismic data are acquired with a sampling frequency of $400 \mathrm{~Hz}$ and are processed on site at the datalogger; the amplitude $A$ (one value per second) is calculated and recorded according to the formula:

$A=\frac{\sum_{i=1}^{400}\left|v_{i}\right|}{400}$

This allows a continuous recording of data without running out of memory, even though the information concerning the frequency of the signal gets lost in the process.

Mean flow velocity between two cross-sections equipped with seismic or ultrasonic sensors can be computed as the ratio of their distance to the time elapsed between the passage of the debris flow at the gauging sites (Marchi et al., 2002). Another technique for assessing mean debris-flow velocity between two monitored cross-sections is the crosscorrelation of recorded data (Arattano and Marchi, 2005). The cross-correlation function, $\phi_{x y}$, is defined as:

$\phi_{\mathrm{xy}}(\tau)=\sum_{t=0}^{M-1} x_{t} y_{t+\tau}$

where $x_{t}$ is the function expressing the signal recorded at the first, upstream station at the time $\mathrm{t}$ and $y_{t+\tau}$ is the function expressing the signal recorded at the second, downstream station at the time $\mathrm{t}+\tau ; \tau$ is the time lag (unknown) elapsed between the recording of the two time series. Cross-correlation has the advantage of permitting the assessment of mean flow velocity even if the recordings do not lead to the objective recognition of a common feature (typically the passage of the debris-flow front) at the two cross-sections.

The measurement of the flow stage and the assessment of velocity provide the elements for estimating the volume of debris-flow surges. The volume of a debris-flow surge flowing through the cross-section is assessed by calculating the integral (Arattano, 2000):

$V=\int_{t_{0}}^{t_{f}} U A(t) d t=U \int_{t_{0}}^{t_{f}} A(t) d t$

where $A(t)$ is the cross section area occupied by the flow at the time $t, U$ is flow velocity (assumed constant and equal to mean front velocity), $t_{0}$ is the time of arrival of the surge at the gauging site and $t_{f}-t_{0}$ is the duration of the debris flow. This approach, whose approximations are discussed in Marchi et al. (2002), can be applied only in cross-sections in which the debris flow did not cause significant topographic changes. 


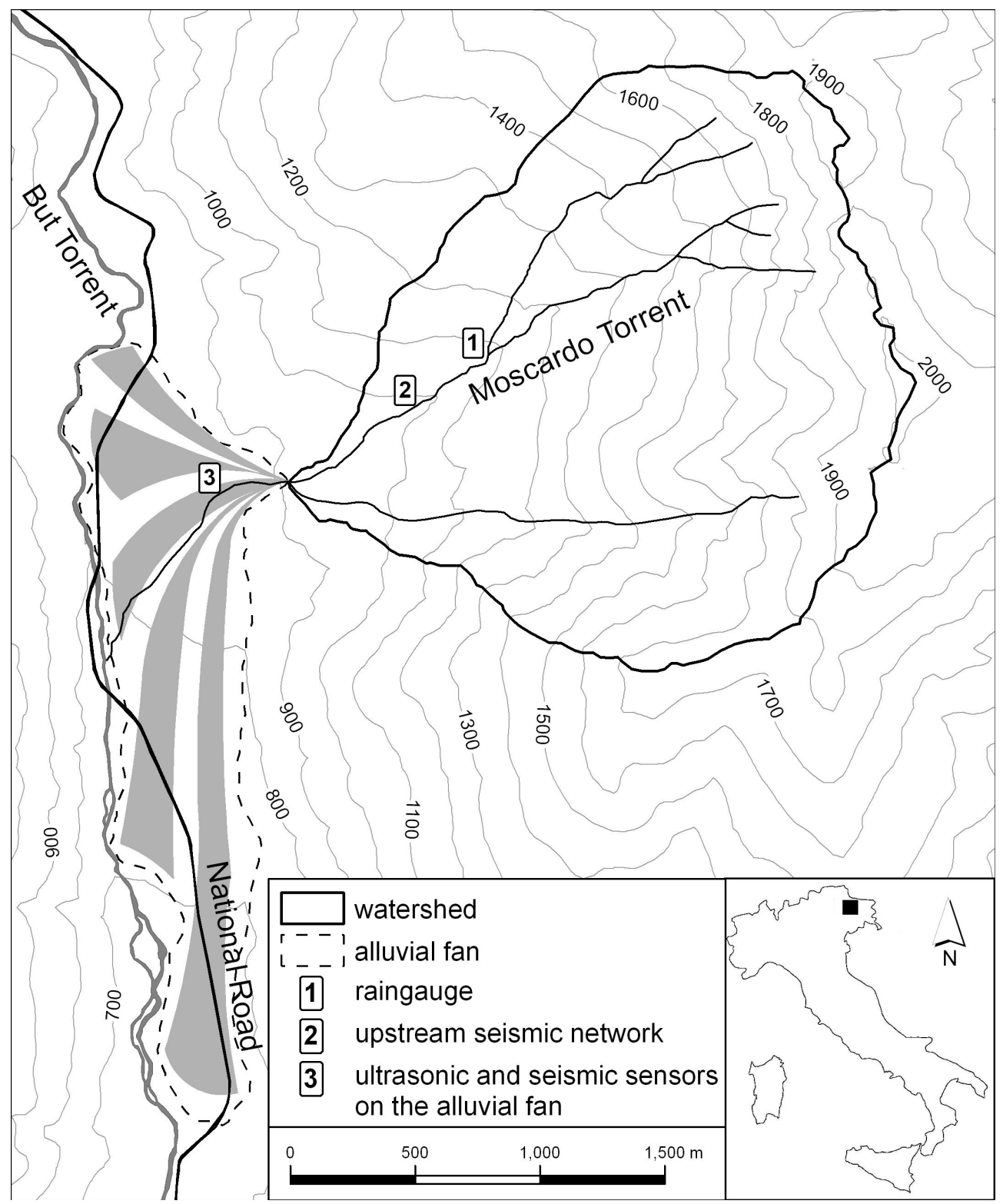

Fig. 1. The Moscardo Torrent basin, its alluvial fan and the monitoring equipment working in the summer of 2006: (1) rain gauge; (2) upstream seismic network; (3) ultrasonic and seismic sensors on the fan.

\section{The debris flow of 24 August 2006}

\subsection{Rainfall data}

The debris flow of 24 August 2006 was triggered by a shortduration rainstorm, which occurred from 13:30 to 16:00 LT. The surge was recorded on the alluvial fan at 15:50; the initiation of the debris flow in the upper part of the basin can be estimated at $15: 40$, i.e. in the final phase of the storm. The accumulated rainfall at the time of debris-flow initiation is $25 \mathrm{~mm}$, with an average intensity of $11.5 \mathrm{~mm} \mathrm{~h}^{-1}$. These values are consistent with those observed for previous events (Deganutti et al., 2000).

\subsection{Seismic records at the upstream monitoring site}

Figure 3 shows the graphs of amplitude (Eq. 1) versus time, recorded at the upstream seismic network.

The duration of the event is different for the different graphs and is longer in the graph of the seismometer S1 which displays also higher values of magnitude: this can be referred to the higher sensitivity of sensor S1.

The graph recorded by the seismometer $\mathrm{S} 1$ shows the presence of an abrupt increase of the signal that can be ascribed to the arrival of the main front at the sensor site. The abrupt increase is subsequently followed by a gradual decrease of 


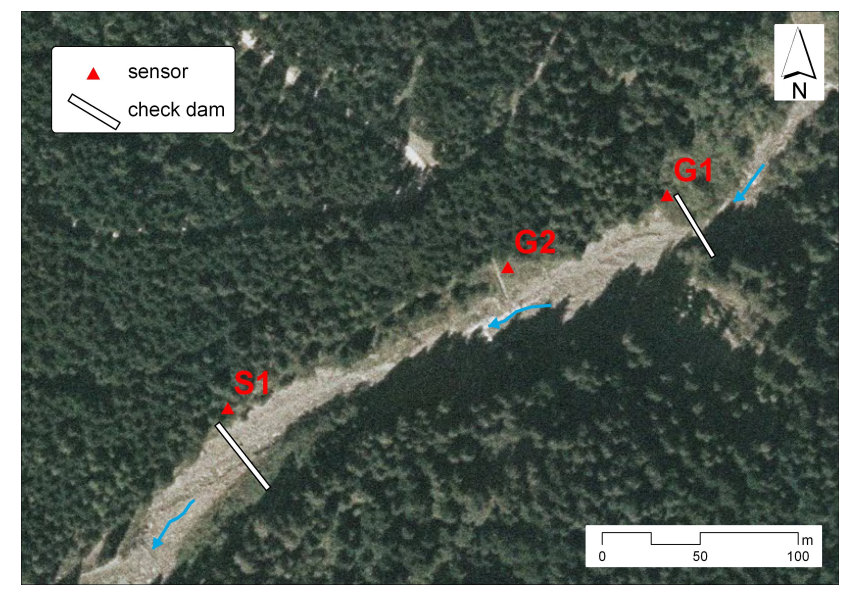

Fig. 2. Plan view of the channel reach instrumented with seismic sensors. The labels G1 and G2 indicate the upstream detectors (geophones type 2) and S1 the downstream seismometer (type 1).

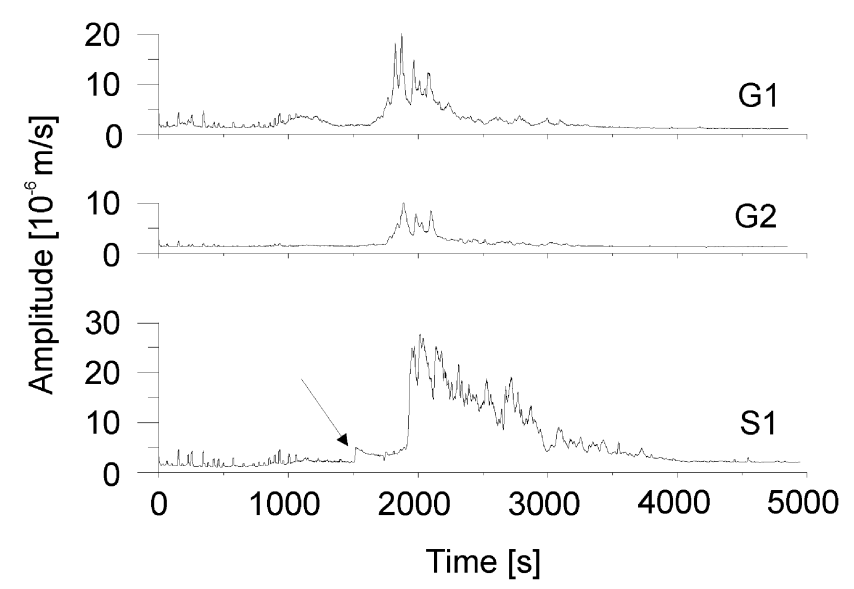

Fig. 3. Graphs of amplitude vs. time recorded by the upstream seismic network. The arrow indicates a small peak that has preceded the arrival of the debris-flow wave at the $\mathrm{S} 1$ sensor.

the signal, which is correlated to flow depth that gives to the graph, and consequently to the debris flow wave, the triangular shape often described in literature for this type of flow. Actually, behind the first peak several other peaks can be observed (the second even greater than the first) as the wave was evidently composed by different surges so close to each other as to form a single wave.

In the graph recorded by the upstream geophone G1, which shows a smaller signal than S1 because of its lower sensitivity, it is possible to recognize several peaks as for the S1 graph, particularly the first two peaks with the second greater than the first. However, the increase of the signal is not as abrupt as in the $\mathrm{S} 1$ graph, but the signal appears to increase more gradually. This gradualness of signal increase is even more evident in the G2 graph. The graph recorded by G2 is also significantly smaller than the G1 graph; this dif-
Table 1. Estimation of mean front velocity between the sensors of the upstream seismic network and mean wave velocities estimated with cross-correlation.

\begin{tabular}{llll}
\hline Sensors & $\tau(\mathrm{s})$ & Distance $(\mathrm{m})$ & Velocity $\left(\mathrm{m} \mathrm{s}^{-1}\right)$ \\
\hline G1-G2 & 18 & 88 & 4.9 \\
G2-S1 & 156 & 155 & 1.0 \\
G1-S1 & 184 & 243 & 1.3 \\
\hline
\end{tabular}

ference is probably due to the different installation of the two sensors. G1 is installed at a depth of around $0.25 \mathrm{~m}$ below ground surface, close to the wing of a concrete check dam, whereas G2 is placed in a hole dug in loose debris, which was then filled with concrete. The proximity to check the dam probably facilitates the transmission of the vibrations to the geophone G1: the signal recorded by this latter is not only more intense, but also more detailed. First it shows the presence of a small wave that can then be observed also in the S1 recording (indicated by the arrow in Fig. 3), while G2 did not detect it. Furthermore, the G1 graph shows a more detailed descending limb of the debris flow wave, which instead appears to be shorter and less defined in the G2 graph. Another factor that likely contributes to a stronger signal at G1 is the impact of the debris flow on the channel bed downstream of the check dam.

These characteristics of the different seismic records have been analysed through the cross-correlation of data, which has also been used for the determination of the mean debrisflow wave velocity. In order to calculate the velocity, we need to know the time lag elapsed between the appearance of the event at the upstream station and the appearance of the event at the downstream gauging site. The time lag is obtained as the value of $\tau$ that let the value $\phi_{x y}$ maximum.

The time required by the debris flow to propagate between the first two sensors, according to the cross-correlation results, is of $18 \mathrm{~s}$, whereas the time required by the debris flow to propagate between the first and third sensor is much greater, amounting to $184 \mathrm{~s}$ (Table 1).

A careful analysis of recordings was performed to check the results of cross-correlation. We measured the time intervals between the different peaks appearing in the first two graphs (Fig. 4) and we actually found a very close correspondence between these measures and the value obtained with cross-correlation. The time intervals elapsed between the appearance of corresponding peaks at the two first sensors range between 17 and $21 \mathrm{~s}$, as can be seen in Table 2 . Figure 4 also shows that the first two peaks (P1 and P2) are strongly attenuated (especially $\mathrm{P} 2$ ) in comparison with other peaks.

For a further confirmation of the values found through cross-correlation, the time interval between the inception at the second (G2) and third sensor (S1) has been measured. This interval has resulted as $153 \mathrm{~s}$ and it is coherent with the 


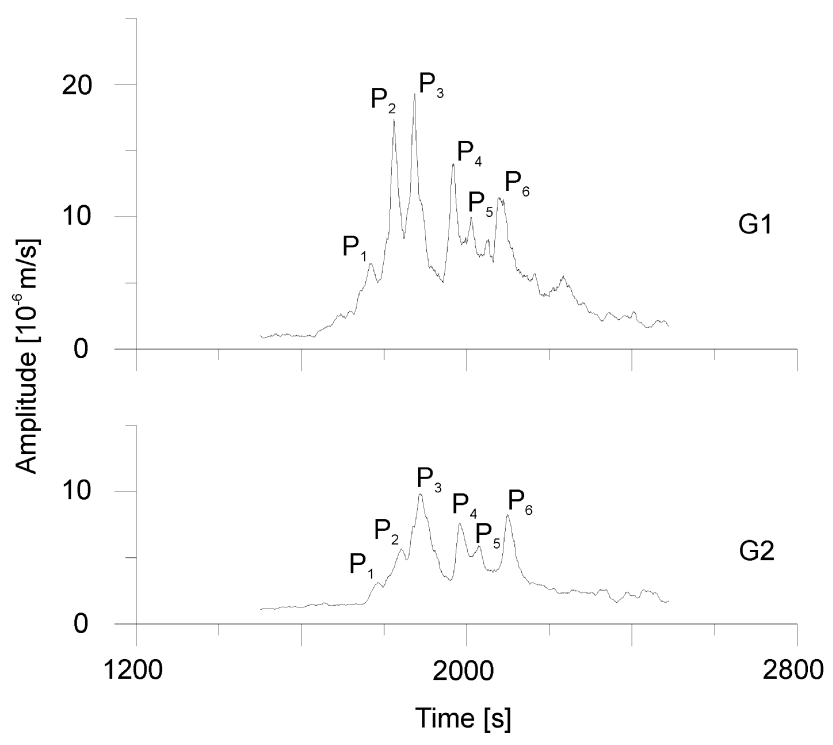

Fig. 4. The two graphs recorded at the geophones G1 and G2 at the upstream seismic network resemble each other and show corresponding peaks that are separated by similar time intervals (Table 2), which are consistent with the value obtained through crosscorrelation.

Table 2. Time intervals between the appearance of corresponding peaks in the two hydrographs recorded at the geophones G1 and G2 (Fig. 4).

\begin{tabular}{llllllll}
\hline Peaks & P1 & P2 & P3 & P4 & P5 & P6 & Mean value \\
\hline $\begin{array}{l}\text { Time } \\
\text { interval (s) }\end{array}$ & 17 & 17 & 15 & 17 & 19 & 21 & 17.7 \\
\hline
\end{tabular}

value of $156 \mathrm{~s}$ found through cross-correlation (the inception of the rise at the first upstream sensor has not been considered because of the fall from the check dam that has altered it). The inception of the seismic wave does not identify an exact arrival time of the debris flow at a specified location, since seismic sensors begin to detect ground vibration before the arrival of the debris flow at the gauging point. However, it is reasonable to expect that the beginning of the rise of the signal at two different sensors occurs with a time lag that depends on the propagation velocity of the debris flow wave. The coherence that has been found seems to confirm this assumption.

A discrepancy can be observed between the results of Table 1 if the time span needed by the debris flow to move from $\mathrm{G} 1$ to $\mathrm{G} 2$, calculated through cross-correlation, $(18 \mathrm{~s})$ is summed to the time span needed by the debris flow to move from $\mathrm{G} 2$ to $\mathrm{S} 1(156 \mathrm{~s})$. This sum $(174 \mathrm{~s})$ is smaller than the calculated time span between G1 and S1 (184s). This discrepancy could be ascribed to the poorer quality of the signal recorded by geophone $\mathrm{G} 2$ due to its different installation

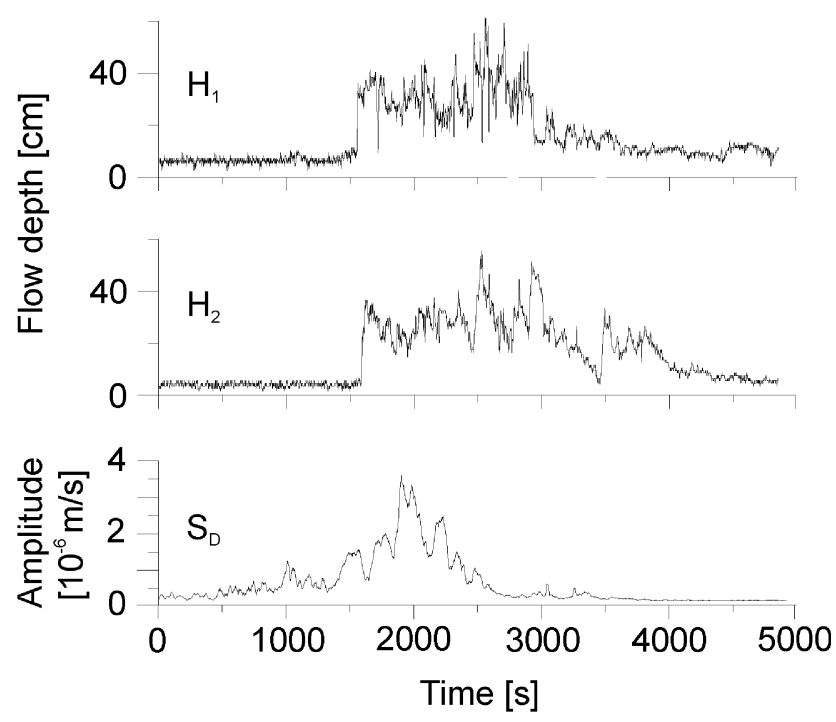

Fig. 5. Hydrographs recorded at the ultrasonic stations on the fan: $\mathrm{H}_{1}$ upstream hydrograph $\mathrm{H}_{2}$ downstream hydrograph. The graph of amplitude versus time $S_{D}$ recorded by the seismic sensor installed on the fan is also shown.

in comparison to $\mathrm{G} 1$, as mentioned previously. The contact with the ground of sensor G2 is certainly looser than that of G1 and this has led to a loss of information in the derived signal that may have affected the results of cross-correlation. However, the influence of this occurrence appears to be only of $6 \%$ (184s vs. $174 \mathrm{~s})$.

\subsection{Seismic and ultrasonic records on the alluvial fan}

Figure 5 shows the hydrographs measured by the ultrasonic sensors on the alluvial fan and the record of the geophone installed at the same site. The average velocity of the wave at the ultrasonic site, calculated through cross-correlation analysis of the signals was $1.6 \mathrm{~m} \mathrm{~s}^{-1}$; a volume of the flowing mass of $5500 \mathrm{~m}^{3}$ has been calculated using Eq. (3).

In the hydrographs recorded by the ultrasonic sensors, even though an abrupt increase in the stage can be observed, this is not followed by the gradual decrease of flow height often observed in debris-flow hydrographs: on the contrary, the flow wave appears to consist of several small surges very close to each other. In the graph recorded by the seismic sensor (Fig. 5), the values of amplitude are low, especially if compared to the upstream records of G1 and G2 (Fig. 4), and the main peak occurs several hundreds of seconds after the first increase of the signal.

Field observations carried out few days after the event revealed the lack of debris-flow deposits along the channel on the alluvial fan (Fig. 6). In addition to the absence of typical features of debris-flow deposits, such as lateral levees observed at the same site for previous events (Moscariello et al., 2002), it is possible to note the limited thickness of 


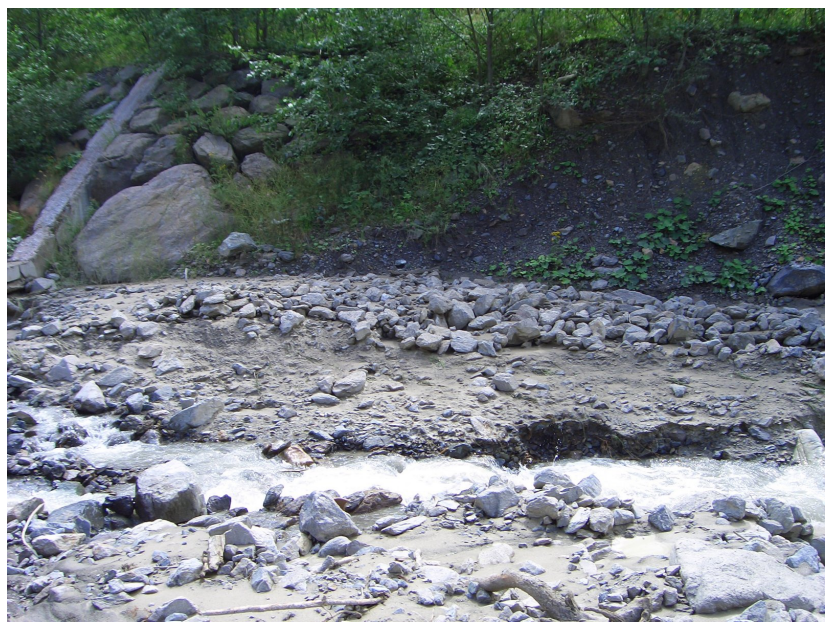

Fig. 6. Deposits of the 24 August 2006 event in the mid-fan area: the low thickness of the deposits and the absence of large clasts are consistent with the small magnitude of the event.

deposits. Moreover, in spite of the widespread presence of coarse debris in the source areas and along the transportation channel and differently from previous debris flows, medium and large boulders are almost lacking in the deposits of the event under study.

Both sedimentological field evidence, instrumental records (low flow depth, and the absence of a well-defined peak) indicate that on the alluvial fan of the Moscardo Torrent, the event of 24 August 2006 was not a debris flow and consisted in the sudden occurrence of a surge of water laden with fine to medium-size sediment.

\section{Discussion}

Data recorded by the monitoring systems contribute to the interpretation of the complex behaviour of the event that occurred on 24 August 2006 in the Moscardo Torrent.

A first comment regards the small and short wave that preceded the arrival of the main front of about $400 \mathrm{~s}$ in the seismic graph S1 of Fig. 3 (it is indicated by an arrow). This peak cannot be ascribed to the fall of the debris flow from a large check dam that is present along the torrent $330 \mathrm{~m}$ upstream of the sensor site as it occurred in previous events (Arattano, 2003). There are two reasons that justify this assertion. Firstly, the peak that can be observed in the graph $\mathrm{S} 1$ is not present in all the other graphs recorded by the geophones, and when it is present (G1 graph) it is not simultaneous. Moreover, the shape of the peak indicated with the arrow in Fig. 3 is very different from that produced by a fall of the front from a check dam (Arattano, 2003). Due to its higher sensitivity, the seismometer was likely capable of detecting a small and fluid wave that had occurred a few minutes before the main debris flow body. Actually the presence

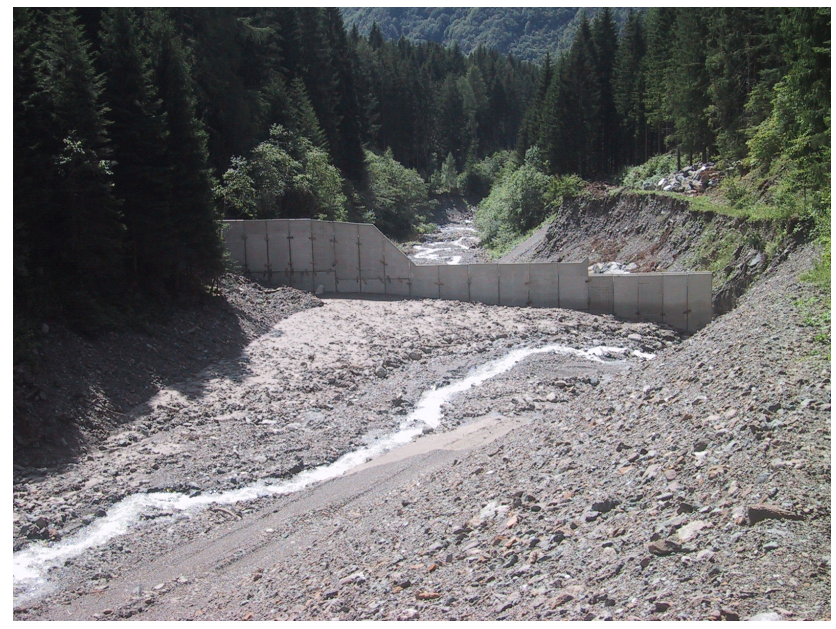

Fig. 7. Fresh debris-flow deposits above the partially built check dam near the sensor S1 (see Fig. 2 for location).

of a small wave preceding the arrival of the main surge can also be observed in the G1 graph even though it appeared earlier and did not show any peak. Liquid precursory surges are a common occurrence in debris flows and have been observed in previous events recorded in the Moscardo Torrent (Marchi et al., 2002).

The explanation proposed for the discrepancy between the time intervals required by the debris flow to propagate from sensor G1 to sensor G2 and then from sensor G2 to sensor $\mathrm{S} 1$ is that the debris flow significantly decreased its velocity between the second and third sensor. The slowing down of the debris flow was likely caused by channel slope reduction due to a grade-control dam, which was under construction at the time of the event (Fig. 7). The deposition of the debris flow on the check dam, even if it occurred at low velocity, caused a strong seismic signal that was clearly recorded by the nearby sensor $\mathrm{S} 1$.

Another relevant topic is the comparison of the signals recorded at the two monitoring sites (i.e. the upstream seismic site and the monitoring site on the alluvial fan). In previous events, the presence of a main front that gave to the graph the typical triangular wave shape had not been always observed at the upstream seismic site. On the contrary, a main front had been always observed on the fan (Arattano, 2000). The opposite took place in the August 2006 event: a debrisflow front is present at the seismic site upstream of the fan apex, whereas it is not clearly present in the graphs recorded at the downstream ultrasonic stations on the fan (Fig. 5).

In addition to changes in the shape of the flow wave, also a substantial attenuation of the phenomenon occurred between the upstream seismic site and the monitoring site on the alluvial fan. In the graph recorded by the seismometer $\mathrm{S} 1$, the amplitude reaches almost $30 \times 10^{-6} \mathrm{~m} \mathrm{~s}^{-1}$ (Fig. 3). These values are comparable with those of previous events that discharged large volumes of material on the fan and showed 
very large hydrographs at the ultrasonic stations. For example, maximum values of amplitude around $30 \times 10^{-6} \mathrm{~m} \mathrm{~s}^{-1}$ were recorded during the event occurred on 8 July 1996. This latter reached the fan with a front height of almost $4 \mathrm{~m}$ and discharged a total volume of about $66000 \mathrm{~m}^{3}$ (Marchi et al., 2002). On the contrary, on 24 August 2006 the hydrograph recorded on the fan showed a maximum height of only about $0.55 \mathrm{~m}$ (Fig. 5) and a volume, assessed by means of Eq. (3), of approximately $5500 \mathrm{~m}^{3}$. The high intensity of the seismic signal at the upstream site was thus not matched by the corresponding magnitude of the event on the alluvial fan. The decrease of event magnitude was caused by debris deposition at the check dam shown in Fig. 7 and in the channel reach between the two monitoring sites (length of about $1 \mathrm{~km}$ ), which also caused the transformation of the debris flow into the less-concentrated surge recorded on the alluvial fan.

Torrent control works implemented in recent years account for the downstream attenuation of the phenomenon between the two monitoring sites. In particular, the channel lining with wide cross-sections and the construction of check dams contributed to stop the debris flow and to transform it into a water surge laden with medium to fine-grained sediment.

\section{Conclusions}

The seismic and ultrasonic recordings of the event that occurred in the Moscardo Torrent on August 2006 further increased the information collected in this catchment since the late 1980s on debris-flow occurrence, intensity, and behaviour. Cross-correlation analysis allowed to reveal that the debris flow had a significant slowing down between the second and third upstream seismic sensor. This is consistent with the ultrasonic recordings on the fan, where the surge between the two ultrasonic sensors had low velocity and low flow depth. These results offer a further example of the performance of different types of sensors as monitoring tools for debris flow and the possibility of processing their data for gaining more information and understanding of debris flow behaviour.

The upstream seismic network, located above the fan apex, has detected the passage of a debris-flow wave with an intensity of the recorded signal comparable to that of previous debris flows, for which the ultrasonic sensors installed on the fan had recorded high flow depths. In the 24 August 2006 debris flow this did not occur, and the hydrographs recorded on the fan depict an event definitely smaller than previous ones with similar magnitude at the upstream seismic network. Moreover, as referred above, recorded hydrographs and field observations indicate that the surge at the monitoring site on the alluvial fan was not a debris flow, and likely consisted in a water wave laden with fine and cobble-size sediments. The transformation of debris flow into a less-concentrated flood wave, and the substantial downstream attenuation of the magnitude can be ascribed to the effects of the torrent control works that have been implemented in the Moscardo basin since late 1990s. The studied event indicates that the hydraulic works in the Moscardo Torrent were effective in reducing the intensity of debris flows of small and moderate magnitude. This attenuating effect proved to be much less relevant for a large debris flow, which occurred in September 2011. The debris flow of September 2011 travelled the whole channel of the Moscardo Torrent and left abundant deposits at the confluence with the receiving stream. The check dams built in the middle sector of the channel prevented channelbed incision, thus avoiding further increase of debris-flow magnitude, but did not stop the flow.

Acknowledgements. We gratefully thank Hiroshi Suwa and an anonymous referee for their help in carefully reviewing the manuscript, which has contributed to improve the quality of the paper.

Edited by: M. Arai

Reviewed by: H. Suwa and another anonymous referee

\section{References}

Arattano, M.: On the use of seismic detectors as monitoring and warning systems for debris flows, Nat. Hazards, 20, 197-213, 1999.

Arattano, M.: On debris flow front evolution along a torrent, Phys. Chem. Earth Pt. B, 25, 733-740, 2000.

Arattano, M.: Monitoring the presence of the debris flow front and its velocity through ground vibration detectors, in: Debris-flow Hazards Mitigation: Mechanics, Prediction, and Assessment, edited by: Rickenmann, D., and Chen, C., Millpress, Rotterdam, 719-730, 2003.

Arattano, M. and Marchi, L.: Measurements of debris flow velocity through cross-correlation of instrumentation data, Nat. Hazards Earth Syst. Sci., 5, 137-142, doi:10.5194/nhess-5-1372005, 2005.

Berger, C., McArdell, B. W., Fritschi, B., and Schlunegger, F.: A novel method for measuring the timing of bed erosion during debris flows and floods, Wat. Resour. Res., 46, W02502, doi:10.1029/2009WR007993, 2010.

Deganutti, M. A., Marchi, L., and Arattano, M.: Rainfall and debris-flow occurrence in the Moscardo basin (Italian Alps), in: Debris-flow Hazards Mitigation: Mechanics, Prediction, and Assessment, edited by: Wieczorek, G., and Naeser, N., Balkema, Rotterdam, 67-72, 2000.

Hürlimann, M., Rickenmann, D., and Graf, C.: Field and monitoring data of debris-flow events in the Swiss Alps, Can. Geotech. J., 40, 161-175, 2003.

Hürlimann, M., Abancó, C., Moya, J., Raïmat, C., and LuisFonseca, R.: Debris-flow monitoring stations in the Eastern Pyrenees. Description of instrumentation, first experiences and preliminary results, in: 5th International Conference on DebrisFlow Hazards Mitigation: Mechanics, Prediction and Assessment, edited by: Genevois, R., Hamilton, D.L., and Prestininzi, A., Casa Editrice Università La Sapienza, Roma, 553-562, 2011. Kogelnig, A., Hübl, H., Suriñach, E., Vilajosana, I., and McArdell, B. W.: Infrasound produced by debris flow: propagation and 
frequency content evolution, Nat. Hazards, doi:10.1007/s11069011-9741-8, 2011.

Liu, K. F. and Chen, S. C.: Integrated debris-flow monitoring system and visual center, in: Debris-flow Hazards Mitigation - Mechanics, Prediction, and Assessment, edited by: Rickenmann, D. and Chen, C., Millpress, Rotterdam, 767-774, 2003.

Marchi, L., Arattano, M., and Deganutti, A. M.: Ten years of debris flows monitoring in the Moscardo Torrent (Italian Alps), Geomorphology, 46, 1-17, 2002.

McArdell, B., Bartelt, P., and Kowalski, J.: Field observations of basal forces and fluid pore pressure in a debris flow, Geophys. Res. Lett., 34, L07406, doi:10.1029/2006GL029183, 2007.

McCoy, S. W., Kean, J. W., Coe, J. A., Staley, D. M., Wasklewicz, T. A., and Tucker, G. E.: Evolution of a natural debris flow: in situ measurements of flow dynamics, video imagery, and terrestrial laser scanning, Geology, 38, 735-738, doi:10.1130/G30928.1, 2010.

Moscariello, A., Marchi, L., Maraga, F., and Mortara, G.: Alluvial fans in the Italian Alps: sedimentary facies and processes, in: Flood \& Megaflood Processes and Deposits - Recent and Ancient Examples, edited by: Martini, P., Baker, V.R. and Garzon, G., Blackwell Science, Oxford (UK), 141-166, 2002.

Navratil, O., Liébault, F., Bellot, H., Theule, J., Ravanat, X., Ousset, F., Laigle, D., Segel, V., and Fiquet, M.: Installation d'un suivi en continu des crues et laves torrentielles dans les Alpes françaises, Journée de Rencontre sur les Dangers Naturels, Institut de Géomatique et d'Analyse du Risque, Lausanne, Suisse, 18 February 2011, 8 pp., 2011.

Okuda, S., Suwa, H., Okunishi, K., Yokoyama, K., and Nakano, M.: Observations on the motion of a debris flow and its geomorphological effects, Z. Geomorph N.F., Suppl. Bd., 35, 142-163, 1980.

Pierson, T. C.: Flow behavior of channelized debris flows, Mount St. Helens, Washington, in: Hillslope Processes, edited by: Abrahms, A. D., Allen \& Unwin, Boston, 269-296, 1986.

Portilla, M., Chevalier, G., and Hrlimann, M.: Description and analysis of the debris flows occurred during 2008 in the Eastern Pyrenees, Nat. Hazards Earth Syst. Sci., 10, 1635-1645, doi:10.5194/nhess-10-1635-2010, 2010.
Schlunegger, F., Badoux, A., McArdell, B. W., Gwerder, C., Schnydrig, D., Rieke-Zapp, D., and Molnar, P.: Limits of sediment transfer in an alpine debris-flow catchment, Illgraben, Switzerland, Quaternary Sci. Rev., 28, 1097-1105, doi:10.1016/j.quascirev.2008.10.025, 2009.

Scotton, P., Genevois, R., Moro, F., Zorzi, L., Girardi, G., and Praticelli, N.: The debris-flow monitoring system of Acquabona Torrent (Cortina D'Ampezzo, Belluno, Italy), in: 5th International Conference on Debris-Flow Hazards Mitigation: Mechanics, Prediction and Assessment, edited by: Genevois, R., Hamilton, D. L., and Prestininzi, A., Casa Editrice Università La Sapienza, Roma, 595-603, 2011.

Suwa, H., Okano, K., and Kanno, T.: Forty years of debrisflow monitoring at Kamikamihorizawa Creek, Mount Yakedake, Japan, in: 5th International Conference on Debris-Flow Hazards Mitigation: Mechanics, Prediction and Assessment, edited by: Genevois, R., Hamilton, D. L., and Prestininzi, A., Casa Editrice Università La Sapienza, Roma, 605-613, 2011.

Tecca, P. R., Galgaro, A., Genevois, R., and Deganutti, A. M.: Development of a Remotely Controlled Debris Flow Monitoring System in the Dolomites (Acquabona, Italy), Hydrol. Process., 17, 1771-1784, 2003.

Yin, H-Y., Huang C-J., Chen, C-Y., Fang, Y.-M., Lee, B-J., and Chou, T-Y.: The present development of debris flow monitoring technology in Taiwan - A case study presentation, in: 5th International Conference on Debris-Flow Hazards Mitigation: Mechanics, Prediction and Assessment, edited by: Genevois, R., Hamilton, D. L., and Prestininzi, A., Casa Editrice Università La Sapienza, Roma, 623-631, 2011.

Zhang, S.: A comprehensive approach to the observation and prevention of debris flows in China, Nat. Hazards, 7, 1-23, 1993.

Zhang, S. and Chen, J.: Measurement of debris-flow surface characteristics through close-range photogrammetry. in: Debrisflow Hazards Mitigation - Mechanics, Prediction, and Assessment, edited by: Rickenmann, D. and Chen, C., 10-12 September 2003, Millpress, Rotterdam, 775-784, 2003. 